\title{
An improved analysis of Mesoscale Convective Systems in the Western Mediterranean using Weather Radar
}

\author{
Tomeu Rigo ${ }^{1,}$ \\ Servei Meteorològic de Catalunya. C. Berlin, 38-46, Barcelona CP 08029 \\ Marc Berenguer \\ Centre of Applied Research in Hydrometeorology, Universitat Politècnica de Catalunya, \\ BarcelonaTech. Jordi Girona 1-3, Edifici C4, S1, Barcelona CP 08034 \\ Maria del Carmen Llasat \\ Dpt. de Fisica Aplicada, Universitat de Barcelona. Martí i Franquès 1, Barcelona CP \\ 08028
}

\begin{abstract}
This article studies the life cycle of the well-organized mesoscale convective systems (MCSs) that affect Catalonia and surrounding regions, using a weather radar composite with sophisticated corrections and lightning data over a full period of five years. Nearly 350 MCSs were identified and analysed for the 2012-2016 period after applying size and duration criteria to 438,000 radar composites. MCSs are responsible for the majority of flood events in the region of interest and in many other areas around the world. We have analysed the main radar parameters and lightning properties, looking for differences between the systems depending on the season of the year. Autumn and spring show the highest frequency of MCSs, but there are considerable differences between their properties for the two seasons. More specifically, lightning activity, maximum reflectivity and duration are higher in autumn than in winter, although the total accumulated rainfall may be lower. This higher convective activity is associated with the warmer sea surface temperature of the Mediterranean and a large number of cyclones that affect the region of analysis.
\end{abstract}

Email address: tomeu.rigo@gencat.cat (Tomeu Rigo) 
Keywords: Mesoscale Convective Systems, Mediterranean Sea, Weather Radar, lightning, precipitation regime

\section{Introduction}

Many authors have analysed mesoscale convective systems (hereafter, MCSs), from different points of view and using different sources (e.g. weather radar, satellites, numerical weather prediction and so on), in order to understand the important role this type of structures plays in many latitudes around the world. In this sense, Doswell III et al. (1996), Gray and Marshall (1998), or Schiesser et al. (1995) found that MCSs are the convective precipitation structure that is most frequently associated with floods at midlatitudes, mainly due to the high degree of organisation, which allows the structure to be maintained for a longer period of time and to become more extensive. Moreover, MCSs are an important link between atmospheric convection and larger-scale atmospheric circulation, as was reported by Houze (2004). This relationship is caused mainly by the strong updrafts that can be observed inside the systems, reaching the tropopause in most cases, and acting as a regulator for heat in the atmosphere. The high degree of organization that convection can reach inside these systems means that severe weather (straight-line winds, hail or tornadoes) and heavy rainfalls can be produced (Palucki et al. 2011, Steiger et al. 2007, Zheng et al. 2013, Punkka and Bister 2015, Schiesser et al. 1995, Schenkman et al. 2011). Parker and Johnson 2000 reported that one of the most significant features of MCSs is their extended life (more than 3 hours and even up to 24 hours in some episodes). The long duration of MCSs was numerically analysed by Lane and Moncrieff (2015) and Moncrieff and Lane (2015), who simulated MCSs in order to find the key features that justified these long life cycles. They found that upshear-propagating and downshear-propagating played a determinant role. Another analysis of the high persistence of some MCSs was carried out by Coniglio et al. (2007), who identified vertical shears in a very deep layer as the main element associated with the duration, based on an analysis of a high number of vertical soundings. Finally, Peters and Schumacher (2015) added a new important aspect to support the long duration of an MCS: the presence of a strong cold pool on the surface, which is generated by the outflow of the first cells and supported by the outflow from later convection (Roux 1988), creating an interaction with the surrounding air that 
can provide the necessary conditions for convective activity to be maintained.

One of the conclusions of Lane and Moncrieff (2015) and Moncrieff and Lane (2015), which coincides with Parker and Johnson (2004)'s work, is that the duration of an MCS varies depending on two main factors: (1) the degree of organisation of the convection at micro and mesoscale into the precipitation system, and (2) the relative position of the main convective region, considering the precipitation system's path. In this sense, many authors have presented different classifications based on weather radar imagery and on the initial classifications of Maddox (1980), Houze Jr et al. (1990), Bluestein and Jain (1985) or Bluestein et al. (1987). The first ones are those proposed by Schiesser et al. (1995) and Parker and Johnson (2000). With more or less similar methodologies and radar data, they defined three main modes, depending on the position of the stratiform area: leading stratiform (LS), trailing stratiform (TS), and parallel stratiform (PS). Moreover, other authors have added other modes, such as: the cluster mode or non-linear system, defined as an MCS without a clear convection organisation (CLU, Rigo and Llasat 2007, Zheng et al. 2013); the quasi-stationary mode (cells start in the upstream of their predecessors and repeat the same trajectory, affecting the same region at all times, Schumacher and Johnson 2005); the training line mode, or a linear system with cells moving in parallel according to the line of convective activity (Schumacher and Johnson 2005); the line without stratiform precipitation (NS, Zheng et al. 2013 or Rigo and Llasat 2007); or a convective region embedded in the stratiform area (Zheng et al. 2013). Other classifications that are less common in the bibliography are those presented by Makowski et al. (2013), who defined 5 modes: symmetric leading line-trailing stratiform (LL-TS); asymmetric LL-TS, leading stratiform; symmetric evolving to asymmetric, and unclassified. Pope et al. (2009) carried out a cluster analysis of satellite imagery, considering the duration (short or long-lived MCSs), and the direction of propagation (from the west or from the east).

Furthermore, the electrical activity inside MCSs shows a high degree of variability, which depends, among other factors, on the type of organisation (Parker et al. 2001). For instance, the aforementioned authors observed peaks of positive cloud-to-ground (CG) flashes during early and dissipating stages of the LS life cycle. On the contrary, PS do not have any stages with significant positive CG flash rates. Moreover, Makowski et al. (2013) found 
that only $21 \%$ of the flashes detected in MCSs were a CG type, and only $13 \%$ of them had positive polarity. They also observed the highest level of total lightning activity in the initial stage and a peak of CG during the last stage. The last aspect of note is the high correlation between the starting time of the flashes and the reflectivity cores in the radar imagery, and the cloud tops of $-52^{\circ} \mathrm{C}$ in the Infrared satellite images. This key aspect was also observed in Steiger et al. (2007) and Lund et al. (2009). The latter also described the different electrical behaviour depending on the region of the MCS where the discharges were produced: ahead of the convective line; in the convective line; in the transition zone; and in the stratiform region. They therefore identified a clear link between electrification and graupel areas detected by weather radar. Mecikalski and Carey (2017) showed that the peak of the intra-cloud flash initiation in the case of an MCS occurred at lower altitudes than for squall lines and at much below than for a supercell, because of the lower strength of the updraft in the first type of convective structures.

The final characteristic associated with MCS is the possibility that they will produce highly efficient precipitation, because the conditions associated with the convection organisation create an environment prone to producing a high ratio of large rainfall amounts from the input water ux (Doswell III et al. 1996). Precipitation efficiency is controlled by certain environmental factors (Market et al. 2003) with the best correlation factor (negative) found in the case of the CIN (that is, convective inhibition). On the other hand, the CAPE presents low values of correlation with precipitation efficiency.

As an example of the magnitude (size and duration) of MCSs, Roca et al. (2014) used satellite data to show that in the tropic regions, MCSs last for nearly 12 hours, while they travel around $250 \mathrm{~km}$. Also using satellite data, Gray and Marshall (1998) found that in the UK the maximum MCS activity took place in June, across mean areas of $25,000 \mathrm{~km}^{2}$, and occurring mainly at night (1800 to 2400 UTC) but being more active in the early morning (0000 to 0600 UTC). Finally, Parker et al. (2001) used a radar network to observe that in Finland the MCSs mostly occurred in July (and they were also the most intense). They were only observed during the warm season, with an average duration of 10.8 hours, and with a high correlation with the diurnal cycle. 
The Mediterranean region is characterised by a complex topography, which interacts with the global atmospheric circulation and inducing regional patterns (Michaelides et al. 2018). Besides, Galanaki et al. (2018) pointed out the peak of convective activity during the Summer in the Mediterranean basin. However, they found an increase in the sea influence on the convective activity during the period from September to November. Other significant results of this research were that the diurnal life cycle has a high impact on the daily convection occurrence and, moreover, that the thunderstorms propagate mainly to the East. The first study to characterise MCSs from weather radar based on a climatology in a part of the Mediterranean basin was carried out by Rigo and Llasat (2007). They observed that nearly half of the 57 MCSs analysed presented a linear organisation (predominantly NS), while the rest were identified as CLU. Their mean area was about 25,000 $\mathrm{km}^{2}$, and as in the UK (Gray and Marshall 1998) the maximum reflectivity was $47 \mathrm{dBz}$, with a top height $12 \mathrm{~km}$. The highest frequency was achieved between 12 UTC and the early afternoon, and the usual displacement was towards E-NE. Moreover, they observed the presence of cyclones associated with some of the systems. However, this study was carried out with a single C-band weather radar and the cases were selected based on different thresholds imposed on the precipitation field on the surface. As a result, many episodes could have been missed because of different casuistic factors such as: (1) the rainfall produced by the MCSs was over the sea; (2) radar volume data were not available (totally or partially), making it impossible to track the structure; (3) episodes where the MCSs had a trajectory larger than the radar coverage; (4) poor quality images due to anomalous effects on the radar.

Knowledge on MCSs in the Mediterranean area is crucial to improve their forecasting and nowcasting. In effect, more that $50 \%$ of the heavy rainfall events recorded in Catalonia are produced by MCSs (Rigo and Llasat 2007), and this kind of system has been responsible for most of the catastrophic floods produced in different parts of the Mediterranean (Llasat et al. 2016). The first MCS identified in this region thanks to the satellite images took place during an October 1982 flood event that affected the eastern part of the Iberian Peninsula, producing $400 \mathrm{~mm}$ of rainfall in a period of 6 hours (Riosalido et al. 1988). Afterwards, the installation of radar networks made it possible to characterise the role played by these systems in specific events, 
like the June 2000 Montserrat event that affected the northeast of Spain, causing $220 \mathrm{~mm}$ of rainfall in 3 hours (Llasat 2001); the September 2002 Gard event in the southeast of France, with over $600 \mathrm{~mm}$ of rainfall (Milelli et al. 2006); or the November 2011 Genoa event in the northwest of Italy with near $200 \mathrm{~mm}$ of rainfall in less than 1 hour (Silvestro et al. 2012).

Following this framework, the final objective of this article is to improve our knowledge of the general and seasonal features of MCSs, and their potential relationship with different meteorological conditions. With this goal in mind, the present paper analyses all the MCSs that developed in Catalonia between 2012 and 2016, considering a large coverage of radar data thanks to the radar network, continuity of the radar imagery for the whole period, and the use of lightning data. The paper has been divided in the following sections: presentation of the data used and the area of study, analysis methodology, results and their synthesis in the conclusions.

\section{Data used and area of study}

Catalonia is a region of $32,000 \mathrm{~km}^{2}$ located in the northeast of the Iberian Peninsula. The complex topography (with heights over 3,000 $\mathrm{m}$ in the north, and the Littoral and Pre-littoral mountain ranges parallel to the coast), and the influence of the warm Mediterranean Sea favour a heterogeneous climate. The air masses that arrive to the region interact with local factors, producing localised phenomena (from severe weather events to snow, droughts and flash floods) that are very complex to forecast. These conditions also affect the meteorological structures and the complexity of MCSs, as shown in Rigo and Llasat (2007) or Martín et al. (2007). Fig. 1 shows the area of study and how radar coverage has changed in the present analysis in comparison to the first study (see also Table 1).

The preliminary analysis (Rigo and Llasat 2007) was based on identifying MCSs through the volume scans carried out by the C-band radar belonging to the Spanish Weather Agency (AEMET) and the Catalan Water Agency's rain gauge network, which provided 5-min data for specific cases. This study was completed by running the algorithm over a continuous radar data set of composite images provided by the Meteorological Service of Catalonia (SMC). Table 1 shows the main differences between both radar data sets. 


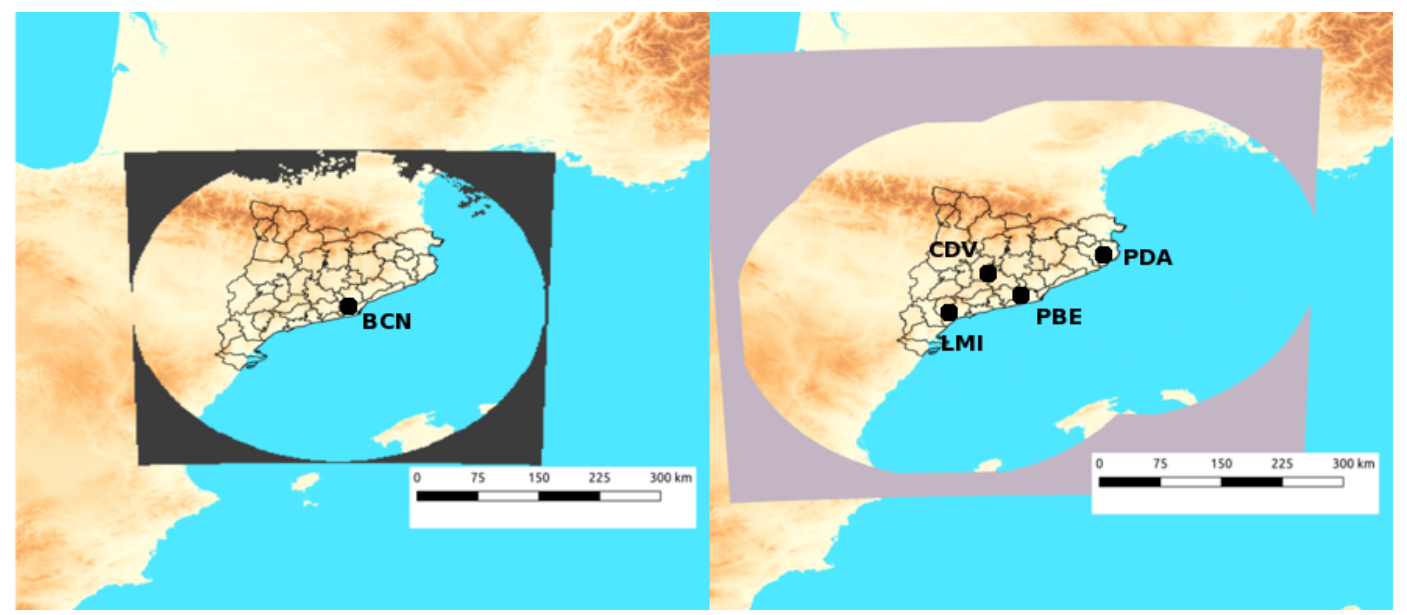

Figure 1: Location of the Region of Interest and the study coverage for the 1996-2000 period with the AEMET radar (left) and the radar coverage of the SMC network used for the present study (2012-2016). Black dots show the radar positions: BCN, AEMET radar (placed in Corbera municipality); the rest of the radars belong to the SMC network, PBE, Puig Bernat (Vallirana); PDA, Puig d'Arques (Cruïlles, Monells and Sant Sadurní de l'Heura); CDV, Creu del Vent (Montmaneu); and LMI, La Miranda (Tivissa).

The sample of MCSs analysed for the 1996-2000 period was based on selected cases associated with heavy rainfall. On the other hand, the sample analysed in this study is made up of all the 6-min radar images for the 20122016 period, and consists of around 438,000 radar composites. This helps to identify all the MCS cases that occurred within the area covered by the radar network, even those that did not produce large amounts of rainfall in Catalonia.

The preliminary study (Rigo and Llasat 2007) that covered the 1996-2000 period was based on one C-Band radar, while we have used a composite of a network of four C-Band radars in the current study. The use of a composite guarantees better coverage and makes it possible to reduce the effects of factors such as path attenuation, beam blockage, the variability of the rainfall profile below the first PPI and beam overshooting. These errors are not too significant with respect to detecting MCSs, but in some cases they could affect the life cycle analysis of these structures, as shown in Rigo and Llasat (2005). The new volume scans have provided an extension of the area of analysis and higher quality near-surface reflectivity estimates, and have 


\begin{tabular}{|c|c|c|}
\hline Version & Old & Current \\
\hline Time resolution & $10^{\prime}$ & 6 \\
\hline Spatial res. & $2 \times 2 \mathrm{~km}^{2}$ & $1 \mathrm{x} 1 \mathrm{~km}^{2}$ \\
\hline $\begin{array}{l}\text { Total area cov- } \\
\text { ered }\end{array}$ & $172,000 \mathrm{~km}^{2}$ & $292,000 \mathrm{~km}^{2}$ \\
\hline Set used & $\begin{array}{l}\text { Discrete (57 cases) (1996-2000) } \\
5 \mathrm{y}\end{array}$ & Continuous (2012-2016) $5 \mathrm{y}$ \\
\hline Corrections & $\begin{array}{l}\text { Doppler (ground clutter re- } \\
\text { moval) }\end{array}$ & $\begin{array}{l}\text { Advanced (EHIMI) Trapero } \\
\text { et al. (2009) Corral et al. } \\
(2009)\end{array}$ \\
\hline
\end{tabular}

Table 1: Main differences between the old analysis (Rigo and Llasat 2007) and the current one.

also introduced an improvement in space and time resolutions. The reflectivity observations used in this analysis are processed with a chain of quality control (Table 2 summarizes them). The corrected volumes are the operational data used in weather surveillance tasks in the SMC, because of the high quality of the product. In order of evaluating the accuracy of the data, the quantitative precipitation estimation generated from surface precipitation estimates is compared with the AWS rainfall measurements, by means of the bias. The results from the period 2012-2016 show values of this skill score moving between 0.4 and 1.7, with a certain seasonal influence (better values are obtained generally in summer, and the worst ones in winter). The lightning data was provided by the Lightning Location System (LLS) of the SMC (XDDE). The LLS is composed of four detectors, working in VHF and LF frequencies, which makes it possible to register both intra-cloud (IC) and cloud-to-ground (CG) flashes separately. Both types of flashes are integrated in a common database, which includes many fields with information about each of the electrical discharges. The spatial location is lower than $1 \mathrm{~km}$ and the detection efficiency exceeds $90 \%$ inside the area covered by the four detectors, and the results are poorer the farther the stroke is from the LLS. More information on the LLS and lightning detection can be found in Farnell et al. (2017).

Two different types of temperature were used to evaluate the area where the MCS grew in the area of analysis. The first one, Sea Surface Temperature (SST), was provided by the Group for High Resolution Sea Surface Temperature (GHRSST) Multi-scale Ultra-high Resolution (MUR) SST data were ob- 


\begin{tabular}{|l|l|}
\hline Correction & Description \\
\hline Signal stability & $\begin{array}{l}\text { Correction of radar rainfall measurement stability using } \\
\text { mountain returns, comparing the distribution average and } \\
\text { current ground clutter echo maps (Sempere Torres et al. } \\
\text { 2003). }\end{array}$ \\
\hline $\begin{array}{l}\text { Ground clutter } \\
\text { identification } \\
\text { and reconstruc- } \\
\text { tion }\end{array}$ & $\begin{array}{l}\text { Identification of non-meteorological echoes (ground and sea } \\
\text { clutter) is based on the fuzzy-logic algorithm of Berenguer } \\
\text { et al. (2006). The reflectivity field in these areas is recon- } \\
\text { structed using neighbours in the horizontal and in the vertical } \\
\text { (Sánchez-Diezma et al. 2001) }\end{array}$ \\
\hline $\begin{array}{l}\text { Vertical profile } \\
\text { of reflectivity } \\
\text { (VPR) }\end{array}$ & $\begin{array}{l}\text { Use of the VPR for improving the estimation of the rain rate } \\
\text { at surface (Franco et al. 2006) }\end{array}$ \\
\hline
\end{tabular}

Table 2: Sophisticated corrections applied to the radar volumes.

tained from the NASA EOSDIS Physical Oceanography Distributed Active Archive Center (PO.DAAC) at the Jet Propulsion Laboratory, Pasadena, CA (http://dx.doi.org/10.5067/GHGMR-4FJ01). The median daily value for the pixels close to the Catalan Coast was calculated for the period of analysis. On the other hand, the Land Surface Temperature (LST) median daily value for the automatic weather stations (AWS) of the SMC network (XEMA) are placed less than $10 \mathrm{~km}$ far to the coastal line. We have selected only values of LST and SST close to the coastal line so that their observations are comparable. Another type of data that could be used in the study is the atmospheric sounding from the Barcelona station. However, this information has not been analysed because of the difficutly of comparing these observations with the LST and SST, the information is only limited to the central coast of Catalonia, being difficult to compare with the LST and SST, analysed for a line of more than 300 kilometres.

\section{Methodology}

The methodology lies in a new approach to identify MCSs, inspired by Rigo and Llasat (2007), but modified based on the authors' experience in the operational field and the computer requirements to analyse near 500,000 composite radar images. Then, the MCSs are identified based on the following criteria: 
- The minimum echo threshold for precipitating areas is $12 \mathrm{dBZ}$.

- Convective rainfall implies reflectivity values equal to or higher than $35 \mathrm{dBZ}$. We have used this threshold instead of the $43 \mathrm{dBZ}$ of Rigo and Llasat (2007) because one of the effects of the corrections shown in table 2 is the enforcement of the convective areas. We have tested the threshold comparing the areas identified using the $43 \mathrm{dBZ}$ over uncorrected imagery and correlating with the detected using different thresholds in the corrected volumes.

- The MCS precipitation structure area is larger than $10,000 \mathrm{~km}^{2}$. This criterion is applied during the whole period in which the system is classified as MCS. The life cycle of the structure is longer, but for the rest of the time the structure will be catalogued as multicell.

- The structure has to be identified in the radar composite for a period of at least 3 hours.

A strict area criterion has been selected because we are interested in the analysis of large structures, which are the cause of most of the main floods in Catalonia in the last years (Rigo and Llasat 2007). Besides, we have tried to use criteria similar to those of the previous analysis, in order to obtain results that could be comparable. For each one of the precipitating structures that verified spatial conditions, certain features were recorded: date of the image, the position of the reflectivity-weighted centroid, the total area, the maximum and mean reflectivity (Zmax and Zmean, respectively), and the \% of convective precipitation. The centroids are calculated similarly as in Rigo and Llasat (2004), this is: $x_{c}=\sum_{i} x_{i} Z_{i} / \sum_{i} Z_{i}$ and $y_{c}=\sum_{i} y_{i} Z_{i} / \sum_{i} Z_{i}$, where $Z_{i}$ is the reflectivity of the i pixel. In total, MCSs were found in 40,082 radar composites. Additionally, a time criterion was also applied to guarantee a certain continuity for the MCSs detected and to avoid any confusion with-non MCS structures. The time condition is applied by means of tracking the precipitating structures along their whole trajectory. The tracking procedure considers the distance between the centroids of two consecutive radar composites, which must be less than $35 \mathrm{~km}$, in order to identify the structure as the same one (Fig. 2). This condition can result in interruptions to life cycles, in cases of merging/splitting, because the centroids of the structures can change their position for many kilometres. However, given our findings, these processes generally mark the beginning or the end of the life 


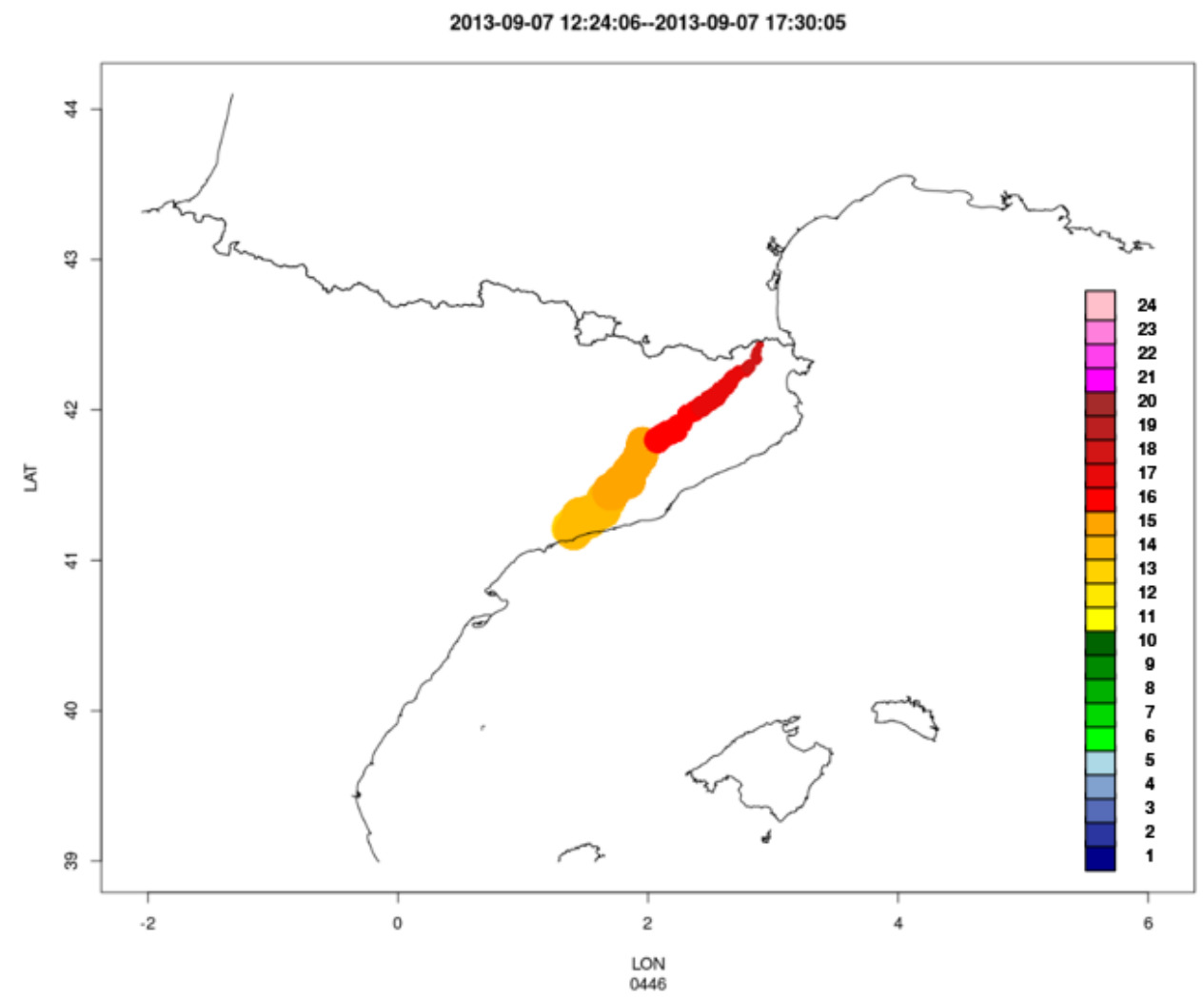

Figure 2: Example of MCS tracking. The dots size correlates with the area, while the colour indicates the observation time (yellow: 12, light orange: 13, orange: 14, dark orange: 15 , light red: 16 , red: 17$)$. 


\section{Results}

Once the MCS data set has been obtained and characterised (i.e. the parameters of section 3, as well as the duration, trajectory and the start and end times), this section presents some statistics to characterise MCS features in the area of study, including the effect of seasonality and time of day. To sum up the analyses, Figure 3 shows the beginning and end points of the trajectories of all the MCSs identified during the period of study. The western and southwestern areas of the region are where most of the MCSs started, while the eastern and northeastern areas are where most of the trajectories came to an end. The areas of initiation are associated with regions where convection triggers, generally in form of isolated cells. When there are the necessary atmospheric conditions, the thunderstorms merge across a line forming the Mesoscale Convective System. There are two main patterns of generation of MCS. The first one, occurring in the western portion of the analysis domain, is strongly influenced by the topography and the sea-land interaction, has a clear influence of the topography and the sea-land interaction, at the time of developing the triggering line. On the contrary, the main cause of the line in the case of the southern structures is a cyclone placed at the East of Catalonia. In this last case, the maritime influence is the main developing factor of the MCS. In both cases, the systems travel across the Catalan territory and dissipate after several hours of activity.

\subsection{Climatic analysis}

The results show the correlation between when the MCSs occur and the time of day (Fig. 4, left). This is associated with the diurnal cycle, with a clear increase in the number of observations after 1200 UTC, reaching their peak at 1900 UTC. These results coincide with those obtained by Nesbitt and Zipser (2003), who analysed a set of MCSs using the Tropical Rainfall Measuring Mission (TRMM) satellite measurements, and with Parker and Johnson (2000), who analysed 88 linear MCSs observed by radar. By using the tracking procedure it is possible to determine the duration of each of the 342 MCSs detected during the period of analysis. Then, we have defined the duration of a MCS as the time between the initial and the last time when the structure is detected as system. As observed in Fig. 4 (right) and in Table 3, most of them lasted between 4 and 8 hours (55\%), with a median duration of 6.8 hours. It is important to clarify that we have only considered 


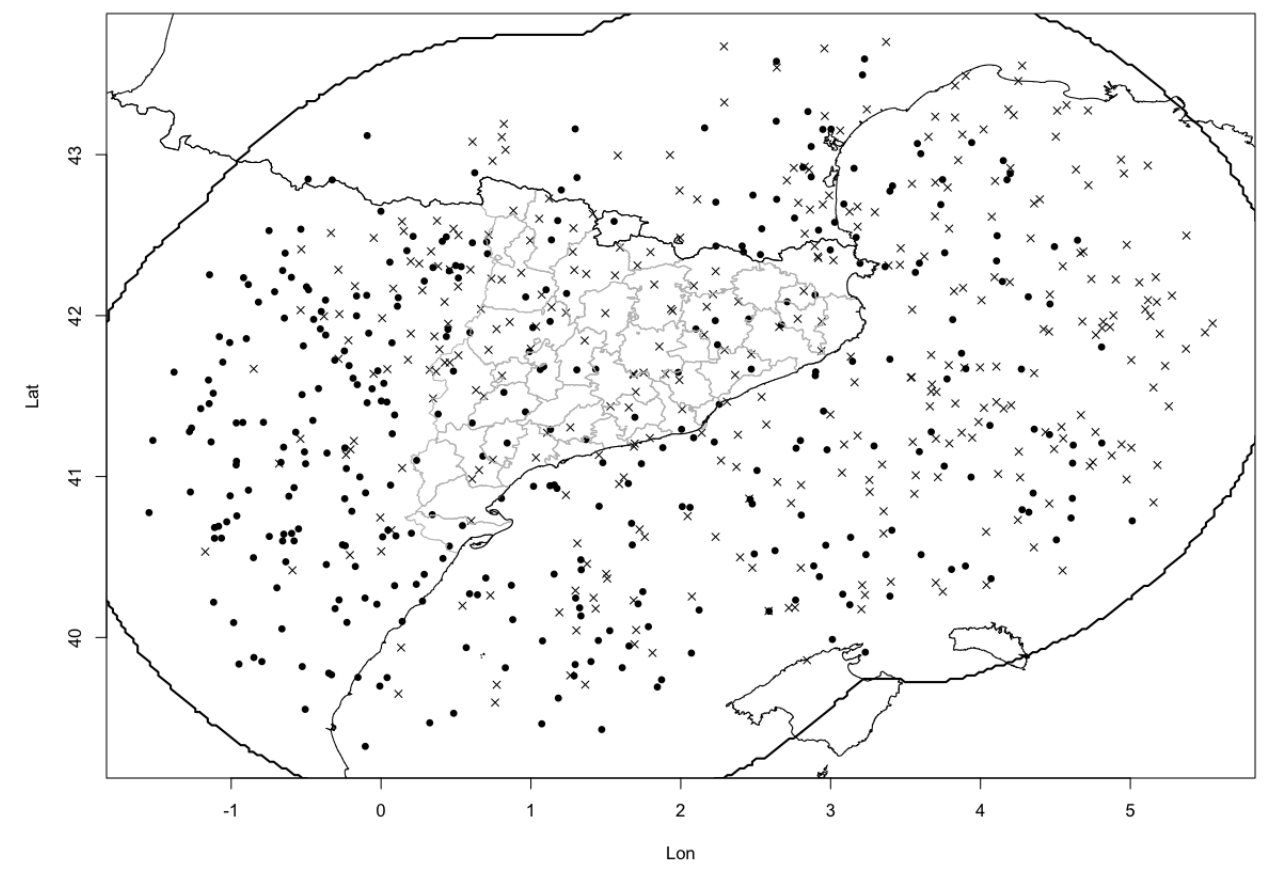

Figure 3: Start (black dots) and end (crosses) points of the trajectories of all MCSs detected during the period of analysis.

those systems with the whole life cycle inside the covered area. Around 11\% lasted more than 15 hours, and it is possible that in some cases the MCSs lasted even longer, but were outside the radar coverage during part of their life cycle. In any case, these values strongly agree with other climatologies, e.g. Punkka and Bister (2015). The median values are similar to those observed in the other European analyses presented in Section 1, but slightly lower. For instance, the median area for the whole period obtained in this study is $22,600 \mathrm{~km}^{2}$, lower than the near $25,000 \mathrm{~km}^{2}$ obtained by other authors. However, as with the duration, it is possible that some MCSs had part of their trajectory out of the range of coverage of the radars network. On the other hand, maximum reflectivity shows median values higher than other analyses. This could be associated with two factors: (1) reflectivity is estimated near ground surface, instead of the usual $1 \mathrm{~km}$ height, or (2) the systems are more intense than in other regions. 

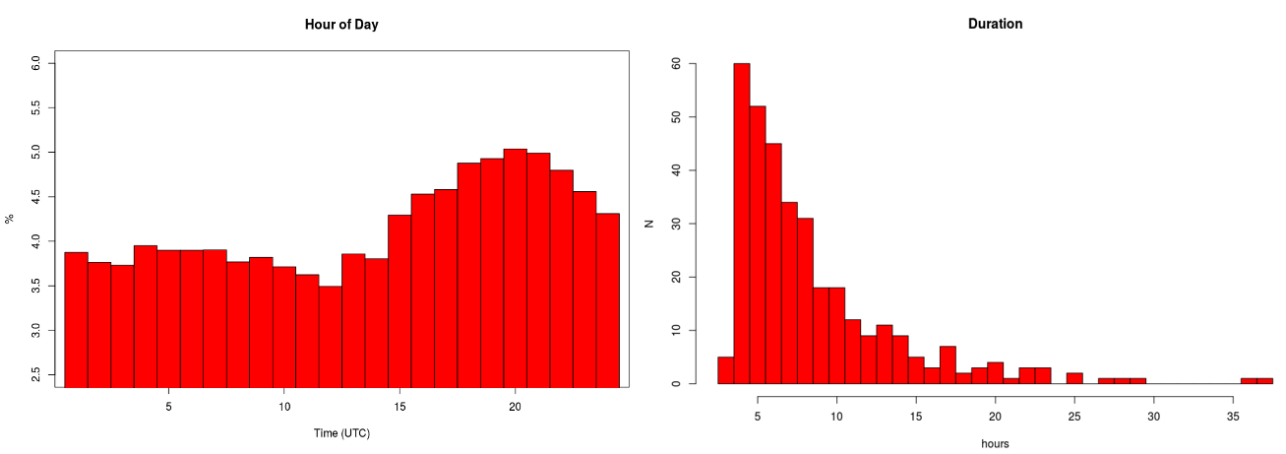

Figure 4: Left: Distribution of the relative frequency of the time of the day for which each MCS is identified, time in UTC (local time is one hour more in winter and two more in the summer). Right: Distribution of the absolute frequency of MCS duration (in hours)

\begin{tabular}{|c|c|c|c|c|c|}
\hline Parameter & Q10 & Q25 & Q50 & Q75 & Q90 \\
\hline Area $_{\text {median }}\left(\mathrm{km}^{2}\right)$ & 15,300 & 18,300 & 22,600 & 28,600 & 40,800 \\
\hline Area $_{\text {Max }}\left(\mathrm{km}^{2}\right)$ & 21,300 & 25,700 & 32,600 & 46,200 & 65,600 \\
\hline$Z_{\text {Max }}(\mathrm{dBZ})$ & 44.5 & 49.5 & 56.0 & 62.0 & 66.0 \\
\hline Distance $(\mathrm{km})$ & 262.2 & 412.3 & 655.7 & 1077.6 & 1875.6 \\
\hline Duration $(\mathrm{h})$ & 4.1 & 4.9 & 6.8 & 10.2 & 15.2 \\
\hline
\end{tabular}

Table 3: Summary of the different parameters associated with the life cycle of the whole set of MCSs detected during the analysed period.

Regarding the direction of the MCSs, Fig. 5 (left) shows that most of the systems have trajectories from west to east or from WSW to NE. In other words, their directions of propagation were from NNE to SSE, while practically no MCSs moved from east to west. Considering the results obtained in Rigo and Llasat (2007), where a clear relationship was found between some of the MCSs identified and closed cyclones at a surface level (Campins et al. 2000), the similarity in direction for most of the cyclone paths observed in the region (see Fig. 5, right) confirms the link between both types of mesometeorological structures.

Finally, Fig. 6 shows how two particular seasons present higher numbers of systems, coinciding with the transitions between cold (from December to February) and warm (from June to August) seasons. We then defined the CO-WA season as the transition from Cold to Warm (mainly covering the months of March and April), which comprised 26.5\% of cases, and the 

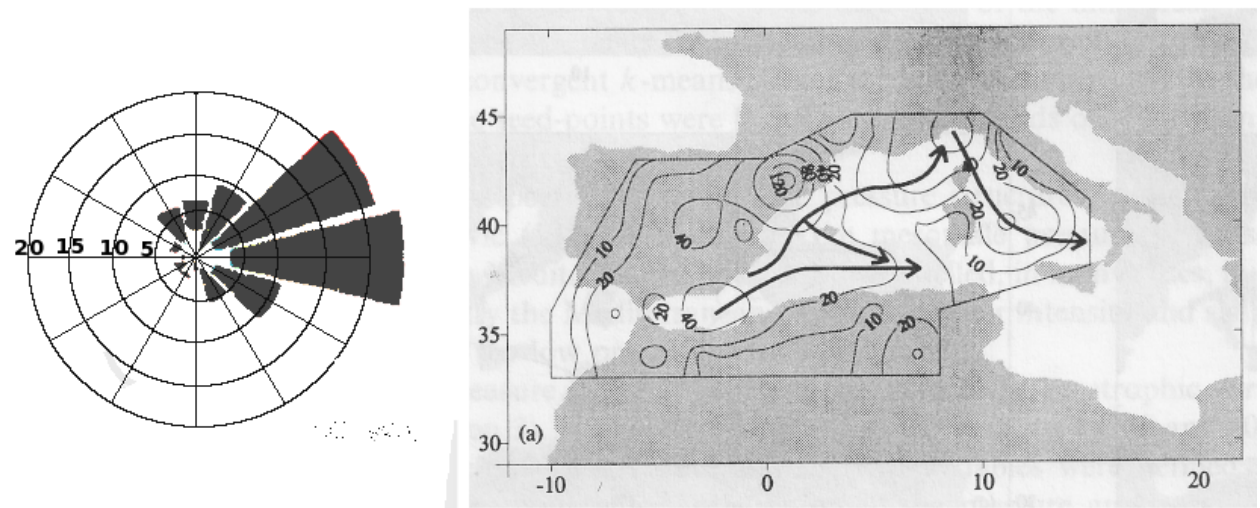

Figure 5: Left: Direction of the trajectories for the MCS data set. Right: median number of cyclones per year and possible cyclone paths for the subjective database (1992-1995) (source: Campins et al. 2000)

WA-CO season as the transition from Warm to Cold (from September to November), comprising $27.4 \%$ of cases. One of the most interesting climatological conditions during both of these phases of the year is that the SST and LST reach similar values coinciding with the season. As a result, the maximum activity of MCS in the region is reached when the contrast between SST and LST is lower.

\subsection{Seasonal behaviour}

As mentioned above, the transition seasons of CO-WA and WA-CO produced the highest level of MCS activity. In this section, we analyse the behaviour of the systems detected in both seasons to illustrate their similarities and differences. We have applied a Pearson's Chi-squared test to the variables, obtaining values of the p-value over 0.05 in all the cases, which means that all of them are statistically significant. In this sense, the comparison of the life cycle of the systems observed in both phases present similar patterns, as shown in Fig. 7. In both examples, the shape of the systems was practically the same, and in agreement with the conceptual model presented in Houze Jr et al. (1989). In the examples in Fig. 7, the areas of convection, which grow by vapour deposition in the mesoscale updrafts, can be clearly differentiated, with vertical developments easily exceeding $6 \mathrm{~km}$, and strong gradients of reflectivity (with a peak of over $45 \mathrm{dBZ}$ ). On the contrary, the stratiform zones, which develop from the advection of ice particles moving 


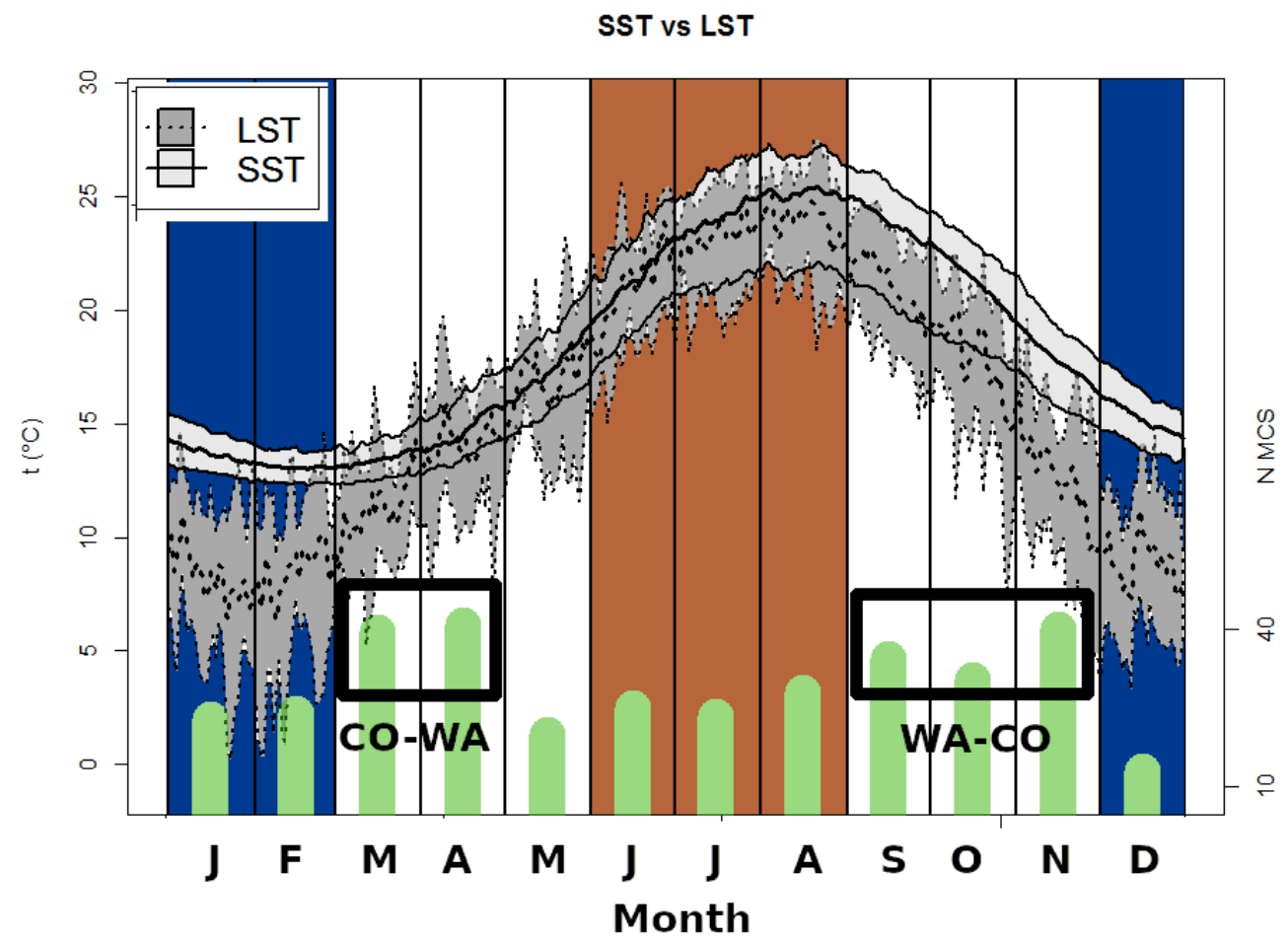

Figure 6: Evolution of the daily average of Sea Surface Temperature (SST)(solid line) and Land Surface Temperature (LST)(dotted line) for the Catalonia region, considering median daily values (2012-2016 period). Shaded areas show the 10-90\% percentiles for the SST (light grey) and LST (dark grey). Monthly distribution of MCSs thorough the year (green histogram). Brown area indicates the warm season and blue one shows the cold season.

from the tops of the convective region (Biggerstaff and Listemaa 2000), with low values of reflectivity (below $30 \mathrm{dBZ}$ ), do not reach $4 \mathrm{~km}$. As in the model shown in Houze Jr et al. (1989), there are echoes over the $4 \mathrm{~km}$., but these do not reach the $25 \mathrm{dBZ}$, in a similar way as shown in figure 4 of that analysis or figure 5 of Biggerstaff and Listemaa (2000).

Fig. 8 shows the predominant direction of the paths. It can be observed how, in the case of the CO-WA season, the main direction is from west to east, while in the case of the WA-CO systems the predominant direction is from SSW to NNE. However, the number of trajectories from north and NNW is notably higher in the case of the CO-WA season. These differences 

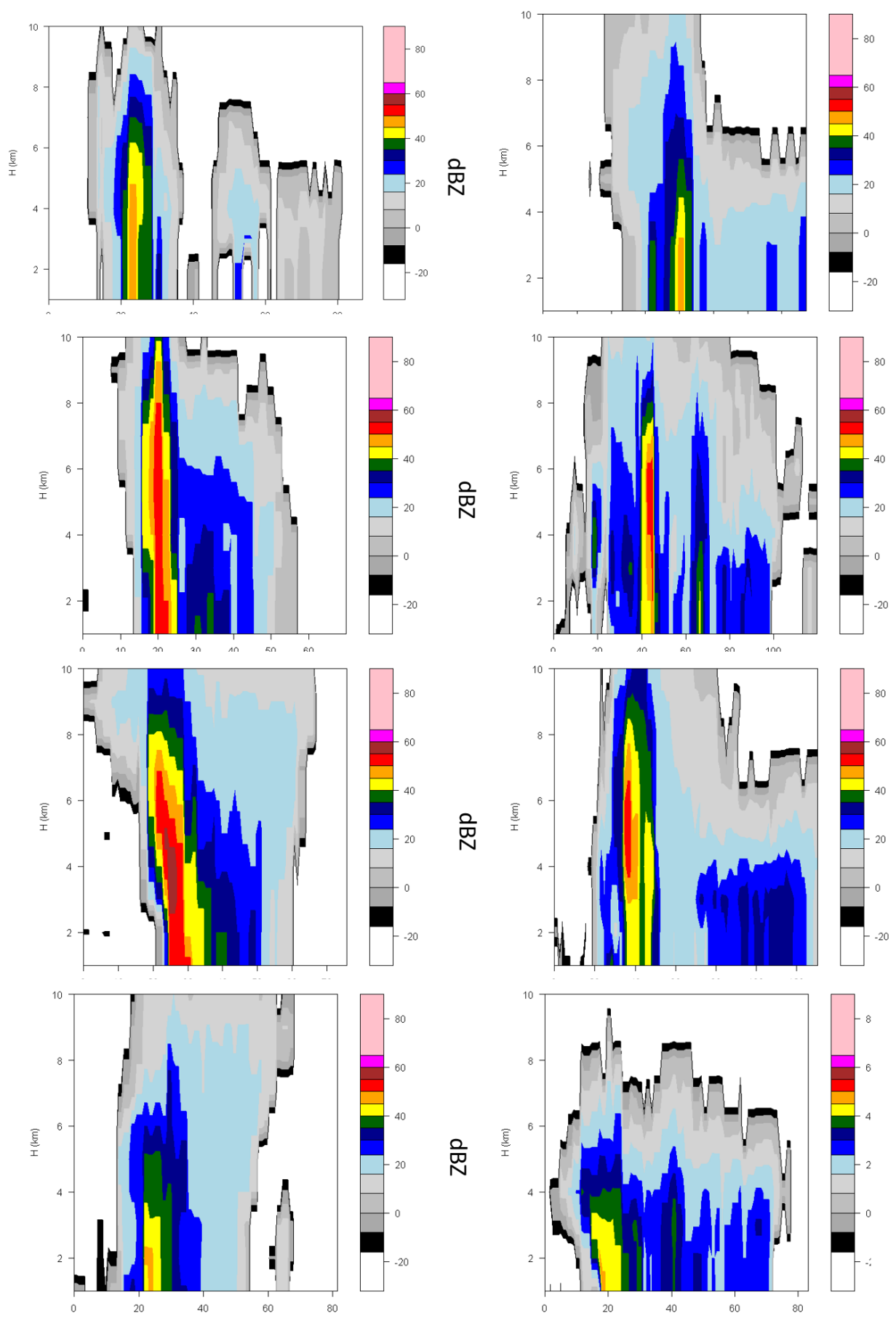

Figure 7: Cross sections parallel to the movement of the system, for two different MCSs registered in the CO-WA (left) and WA-CO (right) seasons, for the different stages of the life cycle (from top to bottom: developing, early mature, maturity, and dissipation) 


\begin{tabular}{|c|c|c|c|c|c|}
\hline Parameter-CoWa & $\mathrm{Q}_{10}$ & $\mathrm{Q}_{25}$ & $\mathrm{Q}_{50}$ & $\mathrm{Q}_{75}$ & $\mathrm{Q}_{90}$ \\
\hline Area $_{\text {median }}\left(\mathrm{km}^{2}\right)$ & 15,900 & 17,800 & 22,900 & 28,400 & 43,300 \\
\hline $\operatorname{Area}_{\operatorname{Max}}\left(\mathrm{km}^{2}\right)$ & 20,800 & 26,400 & 32,500 & 46,500 & 65,300 \\
\hline$Z_{\operatorname{Max}}(d B Z)$ & 40.0 & 45.1 & 50.5 & 55.4 & 61.1 \\
\hline Distance $(\mathrm{km})$ & 268.6 & 390.9 & 677.9 & $1,039.9$ & $1,787.9$ \\
\hline Duration (h) & 4.2 & 5.5 & 6.8 & 10.1 & 15.5 \\
\hline Parameter-WaCo & $\mathrm{Q}_{10}$ & $\mathrm{Q}_{25}$ & $\mathrm{Q}_{50}$ & $\mathrm{Q}_{75}$ & $\mathrm{Q}_{90}$ \\
\hline Area $_{\text {median }}\left(\mathrm{km}^{2}\right)$ & 15,000 & 17,700 & 21,900 & 33,400 & 45,300 \\
\hline $\operatorname{Area}_{\operatorname{Max}}\left(\mathrm{km}^{2}\right)$ & 21,500 & 24,400 & 38,200 & 56,600 & 71,200 \\
\hline$Z_{\operatorname{Max}}(d B Z)$ & 49.5 & 54.0 & 58.0 & 61.0 & 65.2 \\
\hline Distance $(\mathrm{km})$ & 252.4 & 431.9 & 792.2 & $1,329.6$ & $2,508.6$ \\
\hline Duration (h) & 4.2 & 5.3 & 7.8 & 11.8 & 15.1 \\
\hline
\end{tabular}

Table 4: Same as table 3, but for the two data sets: CO-WA (top) and WA-CO (bottom)

between the WA-CO and CO-WA seasons are more clearly visible in Table 4. It can be seen how, except in the case of the average area, all the parameters (maximum area, maximum reactivity, distance covered and duration) indicate higher intensity and strength for systems registered during the WA-CO season. For instance, quantile 50 of the MCSs of the WA-CO season is 7.5 dBZ higher than the CO-WA season. This result agrees with the larger number of cases of floods during autumn (see, for instance Llasat et al. 2005). Larger values of reflectivity are not directly related with the occurrence of floods, but they help. In this sense, a high value of reflectivity is an indicator of a heavy rain rate. Then, according to Doswell III et al. (1996), it is more probable that floods occur when the rainfall rate is elevated for a long time period. This phenomenon can be produced more easily by MCS than other rainfall systems.

\section{Precipitation regimes and lightning activity}

The precipitation regimes in the region vary depending on the season of the year, with a notable connection the weather conditions, modulated partially by the Sea Surface Temperature (Fig. 6). In this sense, the winter season shows a smaller proportion of convective rainfall than the rest of the year, while the higher values of this percentage are registered generally in the summer, with brief but very intense rainfall events (Llasat et al. 2016). These 

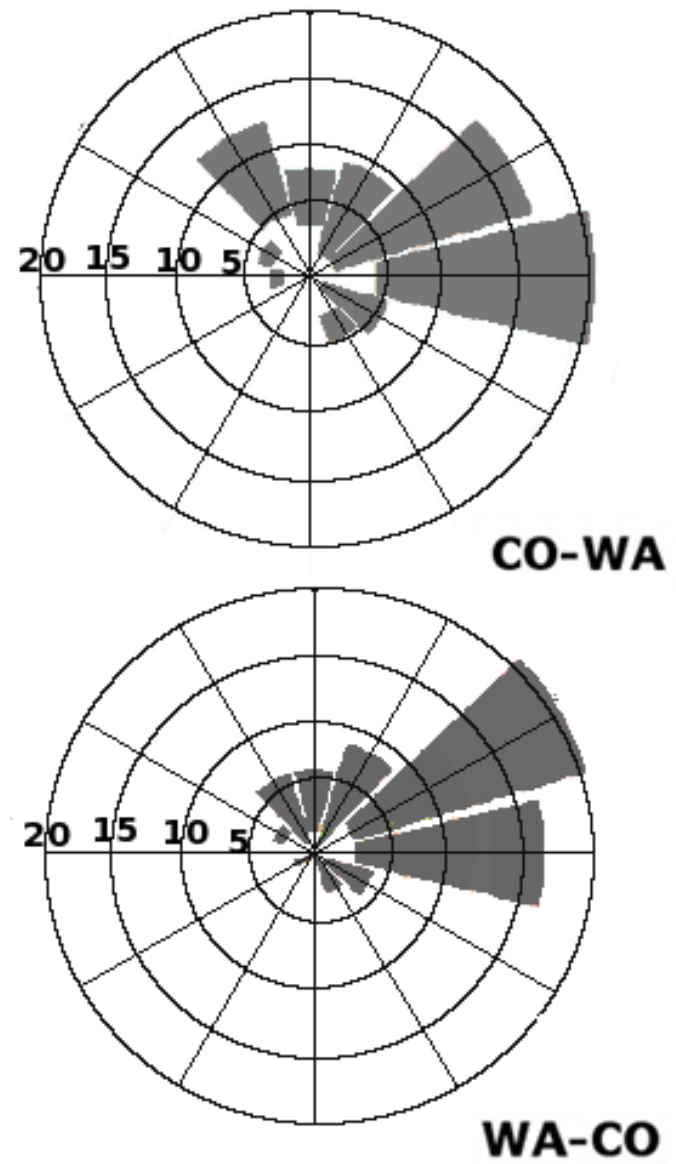

Figure 8: Direction of the trajectories of the CO-WA data set (top) and the WA-CO data set (bottom) MCS

characteristics are also observed in the nature of the precipitation structures shown by the weather radar (Rigo and Llasat 2016 or Rigo et al. 2010). In the case of MCSs, the percentage of convective precipitation (the rainfall associated with echoes exceeding $35 \mathrm{dBZ}$ ) has a median value of $25 \%$ for the whole set of MCSs. However, when comparing both seasons we can see how the MCSs registered during WA-CO presented larger areas of convective rainfall (27\%), ahead of the CO-WA MCSs (20\%). This is coherent with the distribution of convective precipitation observed in Barcelona from the 1-min rainfall rate series at the Fabra Observatory (Llasat 2001). It is mainly explained by the warmer SST during the WA-CO than for the CO-WA, which 

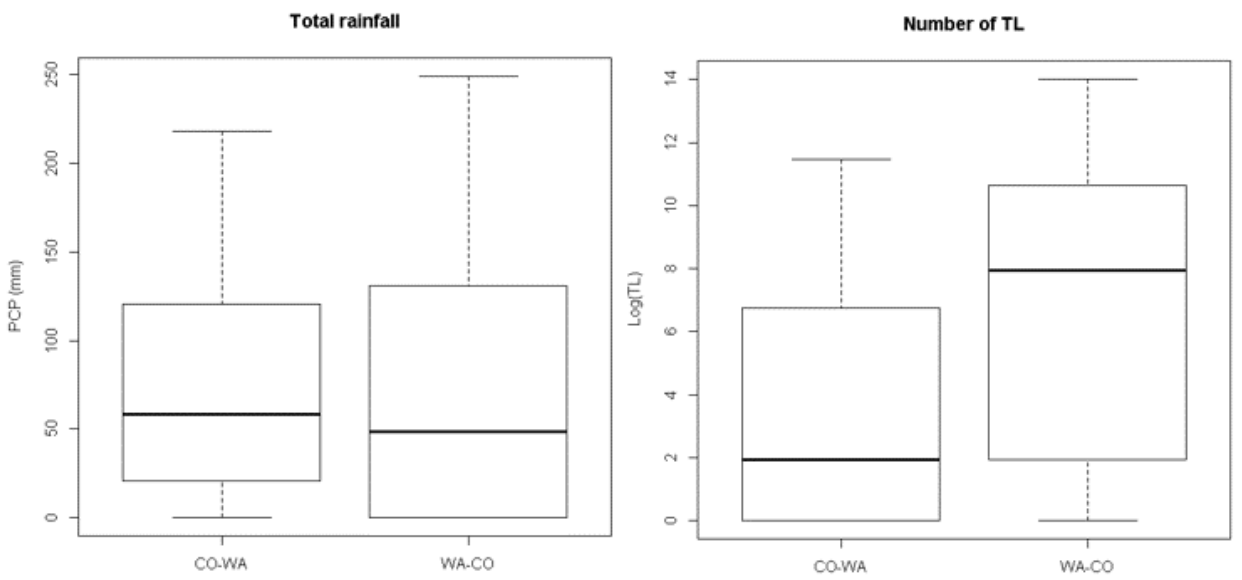

Figure 9: Comparison between the MCSs in CO-WA and WA-CO seasons in terms of total amount of rainfall (left) and total lightning strikes (right).

favours instability at low levels and a greater water vapour content. As shown in Fig. 9, the total estimated precipitation obtained from the weather radar network reached similar values for both seasons, but higher values of total lightning (TL) were recorded during the WA-CO season. This difference can be summarised in the median values of the NTL/QPE rate, with a value of 57.7 flashes $/ \mathrm{mm}$ in the case of CO-WA systems, in comparison with the 786.6 flashes $/ \mathrm{mm}$ registered in the case of the WA-CO MCSs. Another factor that helps the instability and also the organization of the systems is the presence of a cyclone in the vicinity of the region, mainly in the south-eastern sector. The number of cyclones reaches its maximum in autumn, as it is shown for instance in Campins et al. (2011).

\section{Conclusions}

The possibility of accessing a large database with highly accurate corrections of radar volumes has allowed us to carry out a complete analysis of Mesoscale Convective Systems in Catalonia. We wanted to find out if it was possible to get highly qualitative information on MCSs, obtaining a continuous database of radar imagery (2012-2016), from which 342 MCSs were retrieved. Moreover, two main periods with the highest number of 


\section{Acknowledgements}

This study was carried out under the framework of the Spanish projects Cost-Adapt (CTM2017-83655-C2-2-R) and FFHazF (CGL2014-60700R). It was conducted under the framework of the HyMeX Programme. 


\section{References}

Berenguer, M., Sempere-Torres, D., Corral, C., Sánchez-Diezma, R., 2006. A fuzzy logic technique for identifying nonprecipitating echoes in radar scans. Journal of Atmospheric and Oceanic Technology 23 (9), 1157-1180.

Biggerstaff, M. I., Listemaa, S. A., 2000. An improved scheme for convective/stratiform echo classification using radar reflectivity. Journal of applied meteorology 39 (12), 2129-2150.

Bluestein, H. B., Jain, M. H., 1985. Formation of mesoscale lines of precipitation: Severe squall lines in oklahoma during the spring. Journal of the Atmospheric Sciences 42 (16), 1711-1732.

Bluestein, H. B., Marx, G. T., Jain, M. H., 1987. Formation of mesoscale lines of precipitation: Nonsevere squall lines in oklahoma during the spring. Monthly Weather Review 115 (11), 2719-2727.

Campins, J., Genovés, A., Jansà, A., Guijarro, J., Ramis, C., 2000. A catalogue and a classification of surface cyclones for the Western Mediterranean. Int. J. Climatol. 20 (9), 969-984.

Campins, J., Genovés, A., Picornell, M., Jansà, A., 2011. Climatology of mediterranean cyclones using the era-40 dataset. International Journal of Climatology 31 (11), 1596-1614.

Coniglio, M. C., Brooks, H. E., Weiss, S. J., Corfidi, S. F., 2007. Forecasting the maintenance of quasi-linear Mesoscale Convective Systems. Wea. Forecasting $22(3), 556-570$.

Corral, C., Velasco, D., Forcadell, D., Sempere-Torres, D., Velasco, E., 2009. Advances in radar-based flood warning systems. the EHIMI system and the experience in the Besòs flash-flood pilot basin. Flood Risk Management: Research and Practice, 1295-1303.

Doswell III, C. A., Brooks, H. E., Maddox, R. A., 1996. Flash flood forecasting: An ingredients-based methodology. Wea. Forecasting 11 (4), 560-581.

Farnell, C., Rigo, T., Pineda, N., 2017. Lightning jump as a nowcast predictor: Application to severe weather events in Catalonia. Atmos. Res. 183, 130-141. 
Franco, M., Sánchez-Diezma, R., Sempere-Torres, D., 2006. Improvements in weather radar rain rate estimates using a method for identifying the vertical profile of reflectivity from volume radar scans. Meteorologische Zeitschrift 15 (5), 521-536.

Galanaki, E., Lagouvardos, K., Kotroni, V., Flaounas, E., Argiriou, A., 2018. Thunderstorm climatology in the mediterranean using cloud-to-ground lightning observations. Atmospheric Research 207, 136-144.

Gray, M., Marshall, C., 1998. Mesoscale convective systems over the UK, 1981-97. Weather 53 (11), 388-396.

Houze, R. A. J., 2004. Mesoscale convective systems. Rev. Geophys. 42 (RG4003), 1-43.

Houze Jr, R., Biggerstaff, M., Rutledge, S., Smull, B., 1989. Interpretation of Doppler weather radar displays of midlatitude mesoscale convective systems. B. Am. Meteorol. Soc. 70 (6), 608-619.

Houze Jr, R. A., Smull, B. F., Dodge, P., 1990. Mesoscale organization of springtime rainstorms in oklahoma. Monthly Weather Review 118 (3), 613654.

Kolios, S., Feidas, H., 2013. An automated nowcasting system of mesoscale convective systems for the mediterranean basin using meteosat imagery. part i: System description. Meteorological Applications 20 (3), 287-295.

Lane, T. P., Moncrieff, M. W., 2015. Long-Lived Mesoscale Systems in a lowconvective inhibition environment. part I: Upshear propagation. J. Atmos. Sci. 72 (11), 4297-4318.

Llasat, M., Barriendos, M., Barrera, T., Rigo, T., 2005. Floods in Catalonia (NE Spain) since the 14th Century. climatological and meteorological aspects from historical documentary sources and old instrumental records. J Hydrol 313 (1), 32-47.

Llasat, M.-C., 2001. An objective classification of rainfall events on the basis of their convective features: application to rainfall intensity in the northeast of Spain. Int. J. Climatol. 21 (11), 1385-1400. 
Llasat, M. C., Marcos, R., Turco, M., Gilabert, J., Llasat-Botija, M., 2016. Trends in flash flood events versus convective precipitation in the Mediterranean region: The case of Catalonia. J. Hydrol. 541, 24-37.

Lund, N. R., MacGorman, D. R., Schuur, T. J., Biggerstaff, M. I., Rust, W. D., 2009. Relationships between lightning location and polarimetric radar signatures in a small Mesoscale Convective System. Mon. Weather Rev. 137 (12), 4151-4170.

Maddox, R. A., 1980. Mesoscale convective complexes. Bulletin of the American Meteorological Society, 1374-1387.

Makowski, J. A., MacGorman, D. R., Biggerstaff, M. I., Beasley, W. H., 2013. Total lightning characteristics relative to radar and satellite observations of Oklahoma Mesoscale Convective Systems. Mon. Weather Rev. 141 (5), 1593-1611.

Market, P., Allen, S., Scofield, R., Kuligowski, R., Gruber, A., 2003. Precipitation efficiency of warm-season Midwestern mesoscale convective systems. Wea. Forecasting 18 (6), 1273-1285.

Martín, A., Romero, R., Homar, V., de Luque, A., Alonso, S., Rigo, T., Llasat, M., 2007. Sensitivities of a flash flood event over Catalonia: a numerical analysis. Mon. Weather Rev. 135, 651-669.

Mecikalski, R. M., Carey, L. D., 2017. Lightning characteristics relative to radar, altitude and temperature for a multicell, mcs and supercell over northern alabama. Atmospheric research 191, 128-140.

Michaelides, S., Karacostas, T., Sánchez, J. L., Retalis, A., Pytharoulis, I., Homar, V., Romero, R., Zanis, P., Giannakopoulos, C., Buehl, J., et al., 2018. Reviews and perspectives of high impact atmospheric processes in the mediterranean. Atmospheric Research 208, 4-44.

Milelli, M., Llasat, M., Ducrocq, V., 2006. The cases of June 2000, November 2002 and September 2002 as examples of Mediterranean floods. Nat. Hazard Earth Sys. 6 (2), 271-284.

Moncrieff, M. W., Lane, T. P., 2015. Long-Lived Mesoscale Systems in a lowconvective inhibition environment. part II: Downshear propagation. J. Atmos. Sci. 72 (11), 4319-4336. 
Morel, C., Senesi, S., 2002a. A climatology of mesoscale convective systems over europe using satellite infrared imagery. i: Methodology. Quarterly Journal of the Royal Meteorological Society 128 (584), 1953-1971.

Morel, C., Senesi, S., 2002b. A climatology of mesoscale convective systems over europe using satellite infrared imagery. ii: Characteristics of european mesoscale convective systems. Quarterly Journal of the Royal Meteorological Society 128 (584), 1973-1995.

Nesbitt, S. W., Zipser, E. J., 2003. The diurnal cycle of rainfall and convective intensity according to three years of TRMM measurements. J. Climate 16 (10), 1456-1475.

Palucki, J. L., Biggerstaff, M. I., MacGorman, D. R., Schuur, T., 2011. Comparison between low-flash and non-lightning-producing convective areas within a mature Mesoscale Convective System. Wea. Forecasting 26 (4), 468-486.

Parker, M., Johnson, R., 2000. Organizational modes of midlatitude mesoscale convective systems. Mon. Weather Rev. 128, 3413-3436.

Parker, M., Johnson, R., 2004. Structures and dynamics of quasi-2D mesoscale convective systems. J. Atmos. Sci. 61, 545-567.

Parker, M. D., Rutledge, S. A., Johnson, R. H., 2001. Cloud-to-ground lightning in linear mesoscale convective systems. Mon. Weather Rev. 129 (5), $1232-1242$.

Peters, J. M., Schumacher, R. S., 2015. Mechanisms for organization and echo training in a flash-flood-producing Mesoscale Convective System. Mon. Weather Rev. 143 (4), 1058-1085.

Pope, M., Jakob, C., Reeder, M. J., 2009. Objective classification of tropical Mesoscale Convective Systems. J. Climate 22 (22), 5797-5808.

Punkka, A.-J., Bister, M., 2015. Mesoscale Convective Systems and their synoptic-scale environment in Finland. Wea. Forecasting 30 (1), 182-196.

Rigo, T., Llasat, M., 2004. A methodology for the classification of convective structures using meteorological radar: Application to heavy rainfall events on the Mediterranean Coast of the Iberian Peninsula. Nat. Hazard Earth Sys. 4, 59-68. 
Rigo, T., Llasat, M., 2005. Radar analysis of the life cycle of mesoscale convective systems during the 10 june 2000 event. Nat. Hazard Earth Sys. $5,1-12$.

Rigo, T., Llasat, M.-C., 2007. Analysis of mesoscale convective systems in Catalonia using meteorological radar for the period 1996-2000. Atmos. Res. 83 (2), 458-472.

Rigo, T., Llasat, M. C., 2016. Forecasting hailfall using parameters for convective cells identified by radar. Atmos. Res. 169, 366-376.

Rigo, T., Pineda, N., Bech, J., 2010. Analysis of warm season thunderstorms using an object-oriented tracking method based on radar and total lightning data. Nat. Hazard Earth Sys. 10 (9), 1881.

Riosalido, R., Rivera, A., Martin, F., 1988. Development of a mesoscale convective system in the Spanish Mediterranean Area. In: Proc. 7th Meteosat Scientific Usersí Meeting, Madrid. pp. 27-30.

Roca, R., Aublanc, J., Chambon, P., Fiolleau, T., Viltard, N., 2014. Robust observational quantification of the contribution of Mesoscale Convective Systems to rainfall in the Tropics. J. Climate 27 (13), 4952-4958.

Roux, F., 1988. The west african squall line observed on 23 june 1981 during copt 81: Kinematics and thermodynamics of the convective region. Journal of the atmospheric sciences 45 (3), 406-426.

Sánchez-Diezma, R., Sempere-Torres, D., Delrieu, G., Zawadzki, I., i Ambiental, M., 2001. P7. 5 an improved methodology for ground clutter substitution based on a pre-classification of precipitation types.

Schenkman, A. D., Xue, M., Shapiro, A., Brewster, K., Gao, J., 2011. The analysis and prediction of the 89 may 2007 Oklahoma tornadic Mesoscale Convective System by assimilating WSR-88D and CASA radar data using 3DVAR. Mon. Weather Rev. 139 (1), 224-246.

Schiesser, H., Houze Jr, R., Huntrieser, H., 1995. The mesoscale structure of severe precipitation systems in Switzerland. Mon. Weather Rev. 123 (7), 2070-2097. 
Schumacher, R. S., Johnson, R. H., 2005. Organization and environmental properties of extreme-rain-producing Mesoscale Convective Systems. Mon. Weather Rev. 133 (4), 961-976.

Sempere Torres, D., Sánchez-Diezma Guijarro, R., Berenguer Ferrer, M., Pascual Berghaenel, R., Zawadzki, I., 2003. Improving radar rainfall measurement stability using mountain returns in real time. In: 31st International Conference on Radar Meteorology. American Meteorological Society, pp. 220-221.

Silvestro, F., Gabellani, S., Giannoni, F., Parodi, A., Rebora, N., Rudari, R., Siccardi, F., 2012. A hydrological analysis of the 4 November 2011 event in Genoa. Nat. Hazard Earth Sys. 12 (9), 2743-2752.

Steiger, S. M., Orville, R. E., Carey, L. D., 2007. Total lightning signatures of thunderstorm intensity over North Texas. part II: Mesoscale Convective Systems. Mon. Weather Rev. 135 (10), 3303-3324.

Trapero, L., Bech, J., Rigo, T., Pineda, N., Forcadell, D., July 2009. Uncertainty of precipitation estimates in convective events by the meteorological service of Catalonia radar network. Atmos. Res. 93, 408-418.

Zheng, L., Sun, J., Zhang, X., Liu, C., 2013. Organizational modes of Mesoscale Convective Systems over Central East China. Wea. Forecasting 28 (5), 1081-1098. 